\title{
Saccular internal carotid artery aneurysm masquerading as a pituitary macroadenoma
}

\author{
Louise Goldsmith, ${ }^{1}$ Stella Williams, ${ }^{2}$ Nabile Mohsin, ${ }^{3}$ Upendram Srinivas-Shankar ${ }^{4}$
}

'Department of Urology, Wexham Park Hospital, Frimley Health NHS Foundation Trust, Slough, UK

${ }^{2}$ Department of Haematology, Royal Liverpool University Hospital, Liverpool, UK ${ }^{3}$ Radiology Department, St Helens and Knowsley Teaching Hospitals, Prescot, UK

${ }^{4}$ Arrowe Park Hospital, Wirral, UK

\section{Correspondence to}

Louise Goldsmith,

louisegoldsmith@doctors.org.uk

Accepted 15 September 2018

\section{DESCRIPTION}

An 84-year-old woman presented to the emergency department with a 3-day history of progressive binocular diplopia on right-sided horizontal gaze, accompanied with gradual-onset right-sided periorbital headache, vomiting and diarrhoea. Medical history consisted of hypertension and chronic kidney disease, stage 2.

Clinical examination demonstrated right-sided VI cranial nerve palsy, normal pupillary light reaction, visual acuity and fields. No other neurological deficits elicited. No clinical features of hypercortisolism, growth hormone excess or adrenal insufficiency were displayed.

Initial blood tests revealed an acute-on-chronic kidney injury (AKI). Admission estimated glomerular filtration rate was $42 \mathrm{~mL} / \mathrm{min}$, baseline 74 ; admission creatinine $180 \mu \mathrm{mol} / \mathrm{L}$, baseline 142 . An urgent CT head, non-contrast in view of the AKI, was performed. Intravenous fluids were administered. CT revealed a $39 \times 18 \times 14 \mathrm{~mm}$ sellar mass, involving the pituitary fossa, extending into the left and right cavernous sinus, sphenoid sinus and posterior sella turcica.

On the next day, MRI of the pituitary (figure 1), without contrast, revealed a heterogeneous signal in the pituitary fossa adjacent to the right internal carotid artery (ICA).

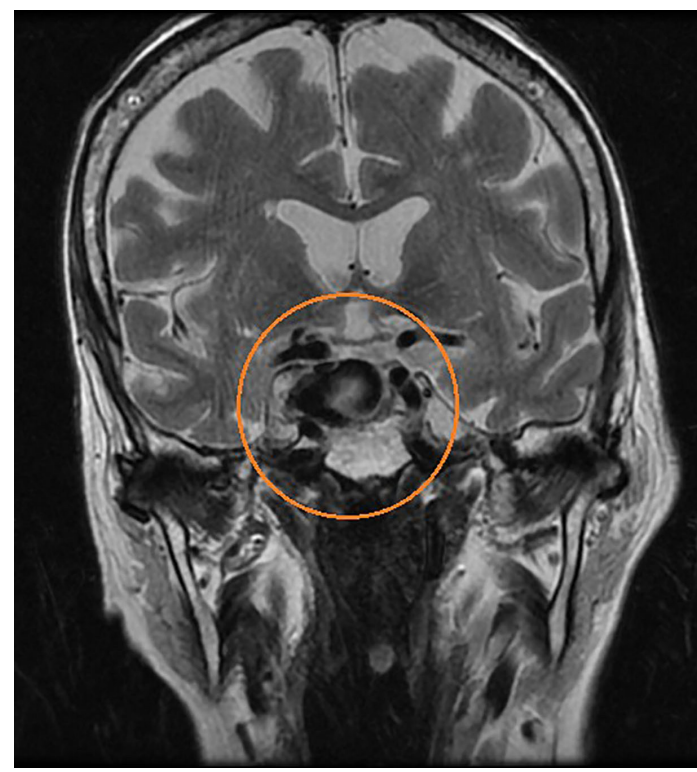

Figure 1 MRI pituitary without contrast. Reveals a heterogeneous signal in the pituitary fossa adjacent to the right internal carotid artery.

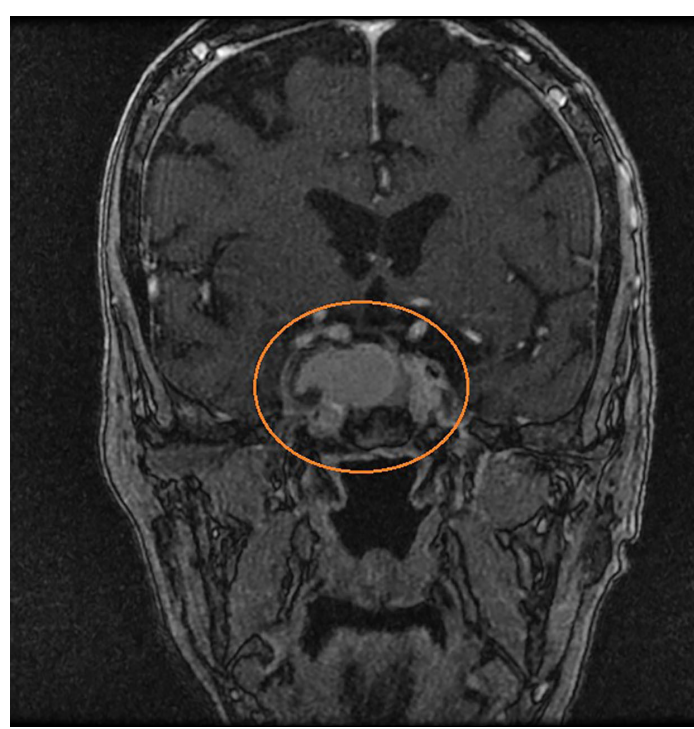

Figure 2 MRI pituitary with contrast. Reveals a homogenously enhancing lesion of the pituitary fossa extending into the sella and suprasellar cistern.

Subsequent blood analysis displayed normal anterior pituitary hormones, 9am cortisol, insulin-like growth factor 1 and serum osmolality.

The diagnosis of a non-functioning pituitary macroadenoma causing a VI cranial nerve palsy was made. The patient was discussed with the

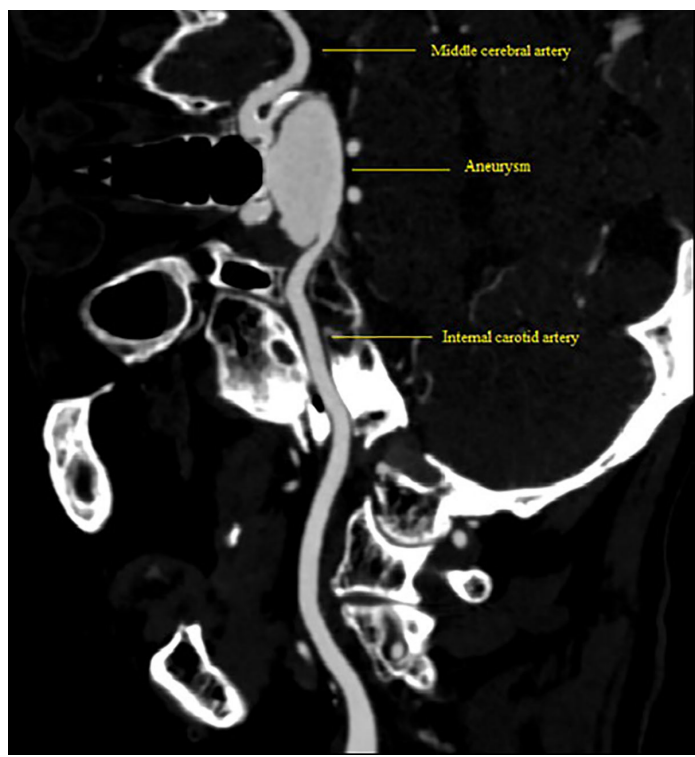

Figure 3 CT angiogram. Curved planar Multiplanar reformation (MPR) demonstrating a large saccular right internal carotid artery aneurysm. 
local neurosurgical centre, transfer was planned for operative intervention.

Prior to transfer, renal function improved after intravenous fluids, enabling a contrast MRI pituitary to be performed (figure 2). This revealed homogenously enhancing lesion of the pituitary fossa extending into the sellar and suprasellar cisterns was identified.

Images were reviewed at the endocrine-radiology multidisciplinary team meeting, where two possible aetiologies for the low signal rim on MRI were discussed (calcification or signal void due to blood flow). With no calcification identified on the previous CT scan, it was concluded that this was likely to be a saccular aneurysm arising from the right ICA, compressing and displacing the pituitary gland to the left. CT angiography confirmed a large right ICA aneurysm (figure 3).

The case was rediscussed with the neurosurgical team, prior to rediscussion with the patient and family. Given the high (up to $30 \%$ ) operative mortality risk, and lower annual risk of aneurysm rupture $(1 \%)$, the patient elected for conservative management.An eye patch was provided to help the diplopia. She regularly attended follow-up for 4 years, during which period she remained complication free, before passing away from an unrelated condition.

Large non-functioning pituitary macroadenomas may present with visual field defects, headache and cranial nerve palsies. It is important to be aware that $1 \%-2 \%$ of intracranial aneurysms project into the sella turcica and therefore giant intrasellar aneurysms may mimic pituitary tumours, with misdiagnosis, potentially resulting in catastrophic consequences. Further, ICA aneurysms with intrasellar extension typically present with mass effect, ${ }^{1}$ and must be excluded prior to neurosurgical intervention.

Large intracranial aneurysms must be considered in the differential diagnosis, when a non-enhanced CT scan shows a well-circumscribed mass without oedema. Cerebral angiography is key to the diagnosis in such situations. ${ }^{2}$
Patient's perspective

Mum would be pleased that you are using her case study to develop our doctors and nurses. The care she received was excellent, and way the options were explained to us as things kept changing was always so clear.

\section{Learning points}

- This case highlights the importance of performing a contrast pituitary MRI to reliably establish the diagnosis of a pituitary lesion.

- Giant intracranial aneurysms must be considered when a non-enhanced CT study shows a well-circumscribed mass without oedema. Cerebral angiography is then key to its diagnosis.

Contributors LG constructed the drafts of this manuscript. SW undertook the initial data collection and edited the initial draft. NM provided information and labels to accompany the images. USS edited the clinical content.

Funding The authors have not declared a specific grant for this research from any funding agency in the public, commercial or not-for-profit sectors.

Competing interests None declared.

Patient consent Next of kin consent obtained.

Provenance and peer review Not commissioned; externally peer reviewed.

\section{REFERENCES}

1 Byrd SE, Bentson JR, Winter J, et al. Giant intracranial aneurysms simulating brain neoplasms on computed tomography. J Comput Assist Tomogr 1978;2:303-7.

2 Ferrante E, Ferraroni M, Castrignanò T, et al. Non-functioning pituitary adenoma database: a useful resource to improve the clinical management of pituitary tumors. Eur J Endocrinol 2006;155:823-9.

Copyright 2018 BMJ Publishing Group. All rights reserved. For permission to reuse any of this content visit

http://group.bmj.com/group/rights-licensing/permissions.

BMJ Case Report Fellows may re-use this article for personal use and teaching without any further permission.

Become a Fellow of BMJ Case Reports today and you can:

- Submit as many cases as you like

- Enjoy fast sympathetic peer review and rapid publication of accepted articles

- Access all the published articles

- Re-use any of the published material for personal use and teaching without further permission

For information on Institutional Fellowships contact consortiasales@bmjgroup.com

Visit casereports.bmj.com for more articles like this and to become a Fellow 